\title{
Guidelines for Marriage Counselling with Zulu Couples
}

\section{Cathy M. Haselau \\ Madhu Kasiram}

\begin{abstract}
This article is based on doctoral research examining the need for and the process required for indigenizing marital therapy to be more applicable to $\mathrm{Zulu}$ couples, and recommends best practice guidelines for marriage counsellors, particularly those from a different culture, or those who have received training in western Eurocentric theory and practice. Four specific values of Zulu culture were indicated as being important when counselling Zulu people. These included basing the counsellor's epistemology on communality as occurs with Ubuntu (Nyaumwe \& Mkabele 2007); needing to practice hlonipha or respect (Rudwick \& Shange 2009) and assisting the couple to include hlonipha in their relations with one another; it is also recommended that the counsellor explores spirituality with the couple and examines the practices that enhance feelings of belonging. These four cultural elements can be incorporated into counselling services when working with Zulu people as outlined in this article.
\end{abstract}

Keywords: marriage counselling, Zulu couples, best practice guidelines, cross cultural counselling.

\section{Introduction}

South Africa is a country with different ways of living; yet many of the indigenous beliefs, values and practices are still marginalized (Ross 2010). This influences access to help for indigenous people and provided the motivation to undertake research which forms the basis of this article. 


\section{Context}

People are born into a socio-cultural context and through language and socialization, they learn to understand the norms and values of their particular family and community which informs their view of reality (Williamson 2006). As a result, we need to 'take a critical stance' towards our 'taken-for-granted ways of understanding the world, including ourselves .... The ways in which we commonly understand the world, the categories and concepts we use, are historically and culturally specific' (Burr 2003:2,3). Bar-On (2003) indicates the need for 'African or indigenous social work', citing different reasons with which the authors agree and which contextualise and motivate this research study. These are: some problems experienced in the West are similar to those experienced in Africa, but there remain problems unique to Africa; Africa does not have the resources to cope with problems; in Africa services might not be offered at all, or 'subject to bureaucratic mania' (Bar-On 2003:29) or used politically to buy loyalty; finally theories informing service is largely Eurocentric and not always mindful of African values and way of life.

Consequences of marginalizing or ignoring specific world views means that people seeking help for their problems will feel misunderstood, and avoid returning for ongoing assistance. The need exists to explore how best to indigenise marriage counselling, allowing couple therapists from a different culture, or Zulu therapists who have been taught western, Eurocentric theories and skills, to provide more relevant assistance.

\section{Theoretical Framework}

In order to understand the meaning experiences have for people, it is necessary to be aware of the recursive impact of culture and social context. In any culture, certain points of view will dominate others. These dominant perspectives will specify the preferred ways of believing and behaving within that culture, which we tend to internalize (Haselau, Kasiram \& Simpson 2015). These dominant constructs tend to blind us to the possibilities that others might offer us. Some cultures have colonized and oppressed others, and the concepts of the dominant culture are then imposed on people of the marginalized cultures. However, because society is interactive and reflexive, the marginalised culture will also influence the dominant culture. Therefore it is important to be aware of the world view of a particular culture, and in couple counselling, how this world 
view would impact the values, beliefs, purpose and process of helping.

In the African world view mind, body and spirit are seen as one, 'holistic in depth and range' (Nwoye 2015:15); and communality and interpersonal relationships in the group are valued. Where there are problems, traditional healing attempts to restore harmony and balance, and focuses on the physical symptoms whilst simultaneously attempting to reintegrate the person with their 'community, the earth and the spiritual world' (Ross 2010:45). In this regard, Larty (2013) suggests the need for reflective activities of 'love and service' (2013:3). This view may be contrary to one which pursues individual success as in Eurocentric practice. The interesting possibility that challenges best couple counselling is that a western-centred perspective is often adopted by marginalised communities themselves. The question then is how much of the traditional, indigenous counselling will actually be relevant and for which groups of people, whilst being eroded by rapid technological communication and modernity.

\section{Research Methodology}

The research study was qualitative, using an exploratory design, to explore complex experiences (Creswall 2007). Bar-On (2003) suggests that in order to indigenise therapeutic methods, it is important to directly ask people who are most knowledgeable, hence the study used Zulu couples, family members and helping professionals.

A purposive snowball sample was used spanning two phases.

\section{The First Phase}

In the first phase, three samples of people were individually interviewed using an unstructured interview schedule. The first sample consisted of $12 \mathrm{Zulu}$ couples (this number allowed for data saturation) who were over 21 (for adult perspectives) and who had been married for more than two years (for there to be 'experience' of marriage). The second sample consisted of 9 family elders who had given relationship advice to their family members and who were willing and able to offer information to the researcher. The third sample comprised 10 Zulu social workers who worked with couples and families in the community. 
The couples were offered to be seen separately or together and interviews were in depth, unstructured conversations to explore the person's life growing up as a Zulu person - their childhood, their courtship, their wedding, and their marriage. Where necessary, a translator who was thoroughly debriefed about the research study, was used.

\section{The Second Phase}

During the second phase, results from phase one were discussed with social workers at FAMSA (the Family and Marriage Society of South Africa) in Durban and in Pietermaritzburg via a group discussion in order to develop best practice guidelines. This sample was a convenience sample based on their availability and professional relationship with the researcher who is also a marriage counsellor.

Data was first thematically analysed (Braun \& Clark 2006). Thereafter the discourses were further analysed by scrutinising the transcripts at a micro level to identify metaphors, words, phrases and topics that were covertly included. The macro view of the discourse was also examined in terms of gender, age and power.

Trustworthiness of qualitative research was accomplished through its credibility, transferability, dependability and confirmability (Babbie \& Mouton 2001; Fossey et al. 2002). Triangulation ensuring credibility and dependability, was achieved by interviewing three samples as well as thorough engagement with the sample (Merriman 2009). The researcher's epistemological and personal reflexivity occurred through wide reading, notes taking and reflective discussions with colleagues and supervisors (Gray 2009), ensuring transferability. An audit trail containing both verbal and written transcripts were scrutinised by supervisors to ensure confirmability (Merriam 2009).

Ethical clearance was secured via the University of KwaZulu Natal. Anonymity and confidentiality was ensured, and signed consent obtained. Participants' comfort was paramount and they were encouraged to stop the interview when tired or uncomfortable, without punity.

A possible critique in the research is that the sample was small, consisting of only Zulu couples, family elders and social workers from particular areas in KwaZulu Natal, and they were interviewed by a middleaged, middle class white woman. However employing the trustworthiness 
dimensions discussed above, mitigated against this concern.

\section{Results and Discussion}

Various themes emerged, but after analysis, conflated into four main themes of values that were identified as meaningful for the respondents in $\mathrm{Zulu}$ marriage:

(1) belonging;

(2) spirituality;

(3) respect (hlonipha); and

(4) ubuntu.

Although these values are not unique to Zulu marriage, respondents accorded them great value in Zulu marriage/community.

There were clear distinctions as well as overlap in terms of meaning in these themes, hence they were regarded as having 'equal' weight in relation to each other. The researcher saw the themes as an equilateral triangle with the central space as ubuntu (see diagram 1 that follows). They each contributed to the strength and depth of meaning of each other.

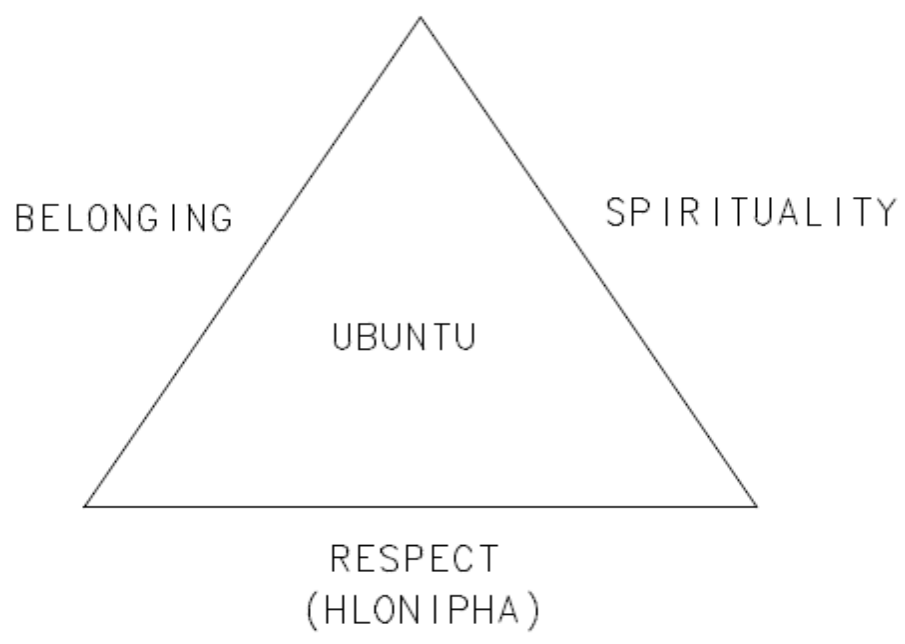




\section{Diagram 1: Themes Noted in the Interviews}

When discussing each theme, the particular value is explained in depth alongside potential problems in the marriage and best practice counselling possibilities. Results from the different samples are jointly presented using these headings, since little difference (mainly in degree/intensity) was noted amongst the responses.

\section{Respect/ Hlonipha}

Respect is a 'feeling of deep admiration for someone or something elicited by their abilities, qualities or achievements' (Oxford English Dictionary).

Although respect is a common value in humankind, in Africa it is a primary value that underpins and upholds the socio-cultural order of society. The different rules and practices of hlonipha may be unknown and foreign to Eurocentric marital counsellors. Rudwick and Shange (2009) describe hlonipha as 'a complex social and linguistic behavioural codex that requires deferential conduct' that is often based on age and gender. As a result, Marcus (2008) and Posel, Rudwick and Casale (2011) criticize the practice of hlonipha as they suggest that it undermines the status of women, and upholds the patriarchal hierarchy of the family. This may be seen as not respecting Afrocentricism, but the quote that follows, offers another point of clarity to this. $\mathrm{Mr}$ M.M. a family elder who was interviewed, clarified:

You don't have to be subservient to be seen as respectful .... It doesn't mean that you are better than other people .... My understanding of respect, you do not respect a person because you are expecting a favour from that person or because that person is bigger than you. That is not the reason for you to respect a person. You respect a person because he or she is a human being. But there is another aspect of it. You must respect a person for what he or she is, you know. ... If a person is a king you must respect that person for being a king .... Maybe you are a very bad person, but because of your role, I do respect you.

The above comprehensive explanation is a good example of how a traditional patriarchal world view has been influenced by modernity, and this from a family 'elder' as well, evidence of influence of modernity to traditionally held 
beliefs about the subservient role of women.

In exploring respect or hlonipha, it was evident that major problems could arise from one member of the couple not using the particular respectful practices that are socially prescribed, either to each other or to members of their families. It is therefore important for the marriage counsellor to be aware of what these practices entail and when they are necessary. Bearing in mind the difficulty in differentiating issues of respect between the person and the position as mentioned above, it is important to comprehensively engage with this value to appreciate how it influences the relationship and what remedial or corrective behaviour is necessary.

Frequent discourses arose in relation to traditional vs. Christian practices; traditional practice and modernity, and practices occurring in rural and urban living. In the study, several couples had one way of living and showing respect to each other whilst in the city, but when they went home to visit the extended family in the rural area, they would revert to the traditional expectations, as to do otherwise was seen as being disrespectful. Again the two contradictory world views are apparent, this time directly evident by the same people behaving differently in different contexts. This is also outlined by Larty (2013) when he discusses differing contexts and multiple perspectives. The influence of context is highlighted below.

In the city men help their wives, yet in the rural family's homestead, they may be shamed for doing this as discussed by the following two husbands:

Mr T.M.: Most of the Zulu's look down upon you if you do that thing. This is not a man, this is a \#*\#* wife, is rude under petticoat, how can you fetch water for the wife? How can you cook? But it's a matter of must, if your wife, if she is working somewhere else.

Mr M.N. Some families, they say if I wash the dishes ... it's like she is holding me with the nose.... it takes a brave man to help his wife if ever you have to.

Hence, respect may mean seeing your spouse as a valuable contributor and partner in the relationship deserving help with 'female' tasks (stereotyping of roles) or as per patriarchy, that the husband's comfort/needs supersede the wife's. The results point to the need for interrogating the changing world view of the parties in the relationship and may be highlighted during formal or 
informal education efforts to embolden and alert recipients to challenge or adjust traditional practices. Technology can here be used advantageously to unpack and bring to the surface multiple and conflicting perspectives in order that thinking and behaviour are deliberate and aligned.

As respect is a basic Zulu value, any signs of disrespect such as shouting, swearing and reactivity as occurs in most marriages, are not complying with the verbal and behavioural expectations of hlonipha, and yet these are inevitable in all marriages. Further, contradictory world views, complicated by pressure to act differently in different environments, may render marital conflict resulting in separation and divorce inevitable. Traditionally, both the husband, and in particular his wife are encouraged to show respect through speaking quietly, and not challenging the other. As a result, problems may be ignored and not dealt with, and so addressing such incidents at a practical level by using an alternative, respectful, structured method of communication is necessary.

Leclerk-Madlala (2008) too discusses how the Zulu wife is discouraged from expressing her opinion and often has no voice - she is expected to live a life of 'muted wifehood'. Rudwick and Shange (2009:69) concur. 'While one could argue that hlonipha as a custom is based on mutual respect between all involved and is best captured by the proverb 'Wohlonipha nxa ufunaukuhlonishwa' (meaning - you must display respect if you want to be respected), it is not so easy to refute that it is primarily married women who bear a heavy burden as a result of hlonipha in a traditional household'. Such unequal treatment of the sexes is based on stereotyping of roles, favouring the male, as per patriarchy and tradition, and challenges the practitioner to work with all contributing influences. This means recognising the conflictual nature of the two world views and how they are adopted differently by the same people at different times.

An example of unequal treatment and stereotyping the role of the daughter-in-law is described by Mrs N.M. a social worker:

Mrs N.M.: With our culture...it [respect] becomes invisible .... they take her for granted. They take advantage of her, and yet they expect, you know, great things from her .... It depends on the upbringing of that particular family.

The FAMSA social workers in this study, were more vocal about unequal 
treatment of the sexes and therefore felt strongly that the couple should be interviewed separately first so that the makoti's (daughter-in-law) voice could be heard. This is also evident in Western marriage counselling that teach constructive communication skills and respectful conflict management. So here a melding of the two approaches is indicated.

Further, to apply best practice principles with regard to respect, 'the social worker her/himself needs to consciously make use of these from the beginning. This will also help break down some of the power imbalances that are the residue of apartheid if the social worker is a different race, as well as the power imbalance inherent in the counsellor/client relationship' (Haselau 2015:186). A helpful starting point to demonstrate respect is in greeting, which in the Zulu community is highly valued, and using the title of 'mama', 'baba', or 'gogo' with the client's surname as suggested by FAMSA social workers. Asking too many questions is viewed as disrespectful in the Zulu community (Rosenblatt \& Nkosi 2007) and therefore it is important to clarify the need for certain questions during the orientation process, and to give permission to clients to refuse to answer if they wish at the outset of counselling.

The need for expressing appreciation can be stressed, with the explanation that appreciation and acknowledgement can increase positive communication and respect. This may be related to traditional praise singing (Haselau 2015) and/or simply teaching the couple to communicate appreciation more regularly, with melding of traditional and modern practices herein evident.

Although there is a broad base of common beliefs, values and practices when showing respect, each couple and their respective family is unique in how they practice hlonipha, and so this needs to be clarified with both members of the couple.

\section{Belonging}

A sense of belonging is a feeling of acceptance into a group (Nugent 2013). Rituals and 'belonging' are closely related in traditional indigenous practice. Fiese, Tomcho, Douglas, Josephs, Poltrock and Baker (2002:382) defined rituals as involving highly 'symbolic communication and convey 'this is who we are' as a group ... and [this] provides a sense of belonging .... Rituals also provide continuity in meaning across generations with the anticipation for repeat performance and an investment that 'this is how our family will continue 
to be' .... When rituals are disrupted, there is a threat to group cohesion'.

Certain rituals and rites of passage resulted in respondents feeling they belonged to the family. These rituals introduce and inform the ancestors or amadlozi about life events, and acknowledged belonging to the family occured throughout a person's life - as a baby (imbeleko), moving into adulthood (umemulo), getting married (paying a dowry or ilobolo and exchanging gifts), and at funerals. In the Zulu culture the amadlozi are very much part of the family, and they are honoured in and through the rituals. As Edwards (2010:213) suggests 'ancestral reverence is fundamental for spirituality. Such religious practice brings experiences of belonging and transcendence'. The aim of family discipline is to teach children about good family and community practices and values, so that eventually they too can become a respected ancestor themselves. The ancestors will only look after and take care of the family members to whom they have been introduced, and who acknowledge and respect them, and if this is not done, bad luck will result (Boyuwaye 2013).

According to the respondents of this study, the value of belonging appeared to have great importance, to the point that when the brides were introduced to the husband's family and community at their marriage, they were introduced through their family of origin and through their ancestors, and the place they belonged to. The process of ilobolo and the various rituals of exchanging gifts resulted in a process to transfer the bride from belonging to her family of origin to belonging to the groom's family, where she becomes the makoti. There was a strict demarcation of roles in traditional families where expectations of the makoti or daughter-in-law were identified and she is expected to work hard at housework, laundry and childcare, even if she is working outside the home. However many couples in this study negotiated their own role expectations, but this was more complex with the Zulu couples due to the possibility of them living in two different worlds (in the city and at the extended family's home), and so conflict can arise when each other's expectations are not met. Larty (2013) discusses this, suggesting that the couple is encouraged to hear and understand each other's conflicting views and expectations during counselling. He even suggests discussing the counsellor's possibly conflicting world view as otherwise this may impact on the service provided.

An added complexity about role expectations is gender and age dynamics, and so either the husband's or the gogo's (the matriarch of the family) views may take priority. In order to belong to her husband's family, 
the makoti or daughter-in-law may be expected to be compliant. According to the respondents, there may often be problems specifically between the sisters and the makoti/daughter-in-law, particularly if the sisters sit back and do not help. Generally it is useful if the mother-in-law can intervene and so the husband may need to address this with his mother. In this study several of the men assisted their wives with childcare and the household chores in their own home if the wife worked outside the home as well, and either reverted back to the traditional roles when visiting family in the rural areas, or faced being shamed by family and community members if they continued to help their wives as seen in the discussion on respect.

Best practice for helping professionals therefore entails negotiation of roles of both the husband and the wife in their own home and in that of their in-laws' home, and how these can reinforce respect. It is important to enable the acceptance of the makoti so she can fully belong to her married family, especially as she is the conduit through which the children learn her husband's family values, norms and practices of respect.

This sense of belonging is also important to address when discussing issues of divorce and separation. As mentioned by the participants of this study, divorce is not acknowledged in the Zulu community - they spoke of the bride bringing her trousseau to the marital home in a kist (which is the same shape as a coffin), and this symbolises that the next time that she leaves the home will be in her coffin as evident in the quotes from a wife and from a family elder that follow:

Mrs A.X.: You go and get married with your coffin. It means that in that home where you are going, you will only be leaving in a coffin...So you will die there.

Mrs N.M.: Even if a person gets divorced, but the in-laws can still keep the makoti ... its normal because this marriage belongs to this family.

As the wife belongs to her husband's family, if the couple separate she may still live within the homestead, or have her own home elsewhere, and she is still able to participate in family rituals; whilst her husband moves on with his life and can even take a second wife. Therefore whether helping a couple or individual to divorce or not, or if a person comes after divorce for counselling, it is relevant to examine how the daughter-in-law can maintain contact with 
her in-laws after divorce or separation, so that she can hold on to that valued sense of belonging. This process is very different to that in western Eurocentric communities where contact with the in-laws is generally diminished. The value of retaining links (and a sense of belonging) to the in-law household may benefit children, who can continue to enjoy the support of the whole family, as well as the divorced wife who will be economically and socially looked after.

\section{Spirituality}

A belief in God (uNkulunkulu) is a strong value in the Zulu community (Thabede 2008). Problems are inevitable when spiritual practices and ideals differ. Although many of the respondents in this study belonged to a particular religion, some of them believed in ancestors while others did not. This is similar to Afeke and Verster's (2004:50) comment that 'views [of Christians] regarding ancestor veneration vary from total opposition, to neutrality, to accommodation'. This aspect of spirituality needs to be clarified with the couple in terms of what they feel comfortable with, and if and how they relate to their ancestors. In the study, there was a continuum regarding the degree to which Christians, for example, participated in family functions. At one end, some indicated that they would not attend at all; others compromised and indicated they will attend but will not be part of the ritual with the ancestors, and will not eat the goat meat; whilst others were quite comfortable to participate in the whole ritual, eating the goat meat and enjoying the function. With regard to church attendance, differences existed in not only which church to attend, but also which daily practices were relevant such as praying, invoking the ancestors by burning mphephe (a plant or herb Helichrysum decorum) and blessing/protecting the home. These need in depth discussion and negotiation by parties in the relationship. Mention is made of 'parties in the relationship' as it is likely that there is influence from family and friends, all of whose views must be included in the counselling, if necessary including these physically in the counselling sessions, an obvious difference between parties that attend western-based marital counselling.

Direct influence by significant others is evident from the following quote from a husband:

Mr M.N. It creates problems, that thing [differing religious beliefs], because the parents they always insist in doing what they still believe 
is right, but if you say no .... you always fight, ... you must be prepared to fight. They can even send you away from home. They say 'Yoh! you are no longer a part of us if you don't do this'.

The above quote illustrates Magezi's (2007:166) description of the impact of conflicting views from the extended family and community: 'Refusal to conform may cause expulsion from the circle of relationships, which aggravates suffering'. As a result, should expulsion occur for whatever reason, he suggests that the koinonia or loving care from the faith community be utilised for support and care as discussed by a husband:

Mr G.X.: My connection to God is through my ancestors .... my protection or whatever is through my ancestors. Yes. You know you always deal with people that you know, or that you ... that you've met. It's not that I can go talk to Allah or Jesus. I've never met him. My protection might be from him, but my connection with Jesus is through my ancestors.

When a particular ritual or rite of passage has not occurred, any marital or family issues might be seen as being due to the fact that the ancestors are angry, and therefore need to be appeased by either completing the ritual or by performing a thanksgiving ritual. To what extent a modern couple may wish to follow this, needs interrogation and negotiation, with counsellors needing to bring all views and parties to the table. It may be necessary that the counsellor may well lead this discussion/negotiation by focussing on heart-based rather than intellectual or head-based communication in this matter of religion and religious and/or cultural practice (Larty 2013).

\section{Ubuntu}

Ubuntu may be defined as 'the reciprocal belief that an individual's humanity is expressed through the personal relationships with others in a community, and in turn other people in that community recognize the individual's humanity' (Nyaumwe \& Mkabele 2007:152). One can immediately identify the relation of this value to 'respect' and 'belonging' which both form the other sides of the triangle discussed earlier.

Ubuntu is a dominant philosophy or world view underlying a Zulu 
person's morals and ethics. It stresses collective identity, solidarity, helping, caring and sharing as well as the emphasis on interpersonal relationships. It is a common world view in Africa, particularly in Eastern, Western and Southern Africa, but it was only in 1995 that Schutte linked ubuntu to the proverb umuntu ngumuntu ngabantu - a human being is a human being because of other human beings (Gade 2011). Krog (2008:212) translates ubuntu as 'a person is a person through other persons' and she suggests that there are two aspects to ubuntu - the first is the emphasis on interconnectedness, and the second that grows from this is that this interconnectedness enables the full potential of the wholeness of both the community, and the individuals that make up the community, thereby empowering both.

Ubuntu is a highly complex philosophy of values and practices, and it can be difficult to understand its nuances fully if one has not been socialised using it. Thus marital counsellors from a Eurocentric background may battle to understand the full implications of $u b u n t u$ values and practices. Poovan, du Toit and Engelbrecht (2006) use Mbigi's description of five elements of ubuntu. The first occurs when African people helped each other 'through a shared will and collaborative spirit' and so were able to cope with extreme hardship (Poovan et al. 2006:18). The second value that is closely linked to the first is the spirit of solidarity between family members and the community that is both practical and spiritual (see the values of spirituality and belonging above). Compassion results from the African person learning from young that everyone is connected, may need and deserves help, and therefore everyone needs to be responsible for others, without expecting anything in return. Such a perspective has a moral and religious bias and may be viewed as an 'ideal' to be aspired to, albeit that lived reality may be different. This may of course be attributed to conflicting ideologies, or circumstances that prevent one from looking after another when unable to care for oneself.

The final two aspects of ubuntu relate to respect, as discussed separately previously, and to dignity, which flows from and is reinforced by respect. There clearly exists a recursive relationship among all these concepts. As Magezi (2007:157) stresses 'the well-being of one meant the well-being of all; when they celebrated, they did it together, and when death occurred, they grieved together'.

In this study the concepts of helping and empowering each other were stressed as mentioned below by a husband and by a family elder: 
Mr B.M.: The black people are community people and we care for each other and we love each other, and it's not about me, it's about my family, it's about the community.

Mrs N.M.: So I believed that if I've got, even if it's a little, so I, I support. I have to support in order for people to, to grow.

The potential problems in this area occur when the couple have different ideas of how to help others. For example they may argue about the extent of help to be given. As mentioned by Haselau (2015), there may also be issues relating to self vs. others. There needs to be a balance between individual, couple and family fun time as well as having stress management. Because of the strong value of family and community, sometimes this takes precedence over individual or couple time, resulting in the makoti spending her time serving the family, and this might breed resentment. Consequently the couple bond is not reinforced and the attraction to each other may be diminished with resulting marital problems.

As the family and community members respect and know each other well, there is a cycle of compassion and caring for and helping each other practically, socially, emotionally and spiritually, and this then reinforces the sense of belonging and connection in traditional communities. In order to translate this into indigenous counselling, the couple need to clarify their own and their partner's beliefs about ubuntu. Once this is accomplished, they can then each look at how to operationalize their vision for the presence of $u b u n t u$ in the couple, family, extended family and community.

\section{Conclusion and Recommendations}

For Zulu couple counselling, the results of the study point to using therapeutic epistemologies and techniques that contain elements of the communality and reciprocity expressed in the African world view and in traditional practices. However, an interesting finding was of the seemingly conflictual and contradictory world views held by couples who waver between traditional Afrocentric views and modern Eurocentric views at different times. This suggests thorough interrogation of the values of respect (hlonipha), belonging, spirituality and ubuntu espoused in the findings of this study, as well as counsellor introspection to ascertain their own covert beliefs that could impact service provision, particularly if they are from a different culture, or have been 
trained using Eurocentric theories and practices. As demonstrated by the use of the equilateral triangle in the model, these four values in Zulu marriages support and enhance each other, otherwise they fail; and therefore all four values need to be explored in depth.

The values that have been found to be central to responsible, Afrocentric counselling need regular appraisal and debate at academic and professional levels to keep pace with an ever-evolving context.

This qualitative study used a small sample to glean rich data. Further research is necessary to understand how other marginalised communities experience counselling; and programme evaluation to refine best practices.

\section{References}

Afeke, B. \& P. Verster 2004. Christianisation of Ancestor Veneration within African Traditional Religions: An Evaluation. Die Skriflig 38,1: 47 - 61. https://doi.org/10.4102/ids.v38i1.419

Babbie, E. \& J. Mouton 2001. The Practice of Social Research. Oxford: OUP. Bar-On, A. 2003. Indigenous Practice: Some Informed Guesses - Self-evident but Impossible. Social Work/Maatskaplike Werk 39,1: 26 - 40. https://doi.org/10.15270/39-1-377

Braun, V. \& V. Clarke 2006. Using Thematic Analysis in Psychology. Qualitative Research in Psychology 3: 77 - 101.

https://doi.org/10.1191/1478088706qp063oa

Burr, V. 2003. Social Constructionism. $2^{\text {nd }}$ Edition. London: Routledge. https://doi.org/10.4324/9780203694992

Creswall, J.W. 2007. Research Design: Qualitative, Quantitative and Mixed Method Approaches. $2^{\text {nd }}$ Edition. Thousand Oaks California: Sage Publications.

Durrheim, K. 2006. Research Design. In Terreblanche, M. \& K. Durrheim. (eds.): Research in Practice: Applied Methods for the Social Sciences. Cape Town: University of Cape Town Press.

Fossey, E., C. Harvey, T.F. McDermott \& L. Davidson 2002. Understanding and Evaluating Qualitative Research. Australian and New Zealand Journal of Psychiatry 36: 717 - 732.

https://doi.org/10.1046/j.1440-1614.2002.01100.x

Gray, D.E. 2009. Doing Research in the Real World. $2^{\text {nd }}$ Edition. London: Sage 
Publications Ltd.

Haselau C.M. 2015 Marriage in Contemporary Zulu Society: Implications for Couple Counselling. Unpublished Doctoral Thesis, Durban, UKZN, School of Social Work.

Haselau C.M., M. Kasiram \& B. Simpson 2015. African Marriage Counselling and the Relevance of Western Models of Counselling. The Social Work Practitioner-Researcher 27,2: 169 - 186. https://doi.org/10.25159/2415$5829 / 367$

Larty, E.Y. 2013. Pastoral Theology in an Intercultural World. Eugene, Oregon: Wipf \& Stock Publishers.

Larty, E. Y. 2003. In Living Color: An Intercultural Approach to Pastoral Care and Counselling. $2^{\text {nd }}$ Edition. London and Philadelphia: Jessica Kingsley Publishers.

Magezi, V. 2007. HIV/AIDS, Poverty, Pastoral Care and Counselling: A Home-based and Congregational Systems Ministerial Approach in Africa. Stellenbosch: Sun Press.

https://doi.org/10.18820/9781920109349

Nugent, P.M.S. 2013. Belonging. PsychologyDictionary.org, April 7. Available at:

https://psychologydictionary.org/belonging/ (Accessed on 20 November 2017.)

Nwoye, A. 2015. What is African Psychology the Psychology of? Theory \& Psychology 1-21.

Nyaumwe, L.J. \& Q. Mkabele 2007. Revisiting the Traditional African Cultural Framework of Ubuntuism: A Theoretical Perspective. Indilinga - African Journal of Indigenous Knowledge Systems 6,2:152 - 163. https://doi.org/10.4314/indilinga.v6i2.26424

Oxford English Dictionary. Available at:

https://en.oxforddictionaries.com/definition/respect (Accessed on 20 November 2017.)

Rosenblatt, P.C. \& B.C. Nkosi 2007. South African Zulu Widows in a Time of Poverty and Social Change. Death Studies 31: 67 - 85.

https://doi.org/10.1080/07481180600995214

Ross, E. 2010. African Spirituality, Ethics, Traditional Healing - Implications for Indigenous South African Social Work Education and Practice. South African Journal of Bioethics and Law 3,I: 44 - 51.

Rudwick, S. \& M. Shange 2009. Hlonipha and the Rural Woman. Agenda 82: 
$66-75$.

Thabede, D. 2008. The African World View as the Basis of Practice in the Helping Professions. Social Work/ Maatskaplike Werk 44,3: 233 - 245. https://doi.org/10.15270/44-3-237

Williamson, K. 2006. Research in Constructivist Frameworks Using Ethnographic Techniques. Library Trends 55,1: 83 - 101. https://doi.org/10.1353/lib.2006.0054

Cathy M. Haselau Social Worker in Private Practice Glenwood Durban cathyhaselau@mweb.co.za

Madhu Kasiram Emeritus Professor in Social Work University of KwaZulu-Natal Durban rdkasiram@gmail.com 